\title{
Metamorphic meta isomer: carbon dioxide and ketenes are formed via retro-Diels-Alder reactions in the decomposition of meta-benzenediol
}

Received 00th January 20xx, Accepted 00th January 20xx DOI: $10.1039 / \times 0 \times x 00000 x$

\author{
Marius Gerlach ${ }^{\mathrm{a}}{ }$, Andras Bodi $^{\mathrm{a}}$ and Patrick Hemberger ${ }^{\mathrm{a} *}$
}

\section{Introduction}

Lignin, a complex, irregular and overfunctionalized macromolecule, is one of the major biomass constituents. It is a waste product of paper production, and is currently intensely discussed and investigated as an inexhaustible and renewable source for fuel and fine chemical production. ${ }^{1-3}$ Its irregularity is due to the varied functionalization and linkages between the monomers and makes it difficult to fully understand its chemistry. ${ }^{4}$ Deoxygenation is, however, incontrovertibly required in lignin valorisation. Straightforward hydrodeoxygenation has indistinct prospects due to the lack of sustainable hydrogen sources.5, 6 Non-catalytic and catalytic fast pyrolysis techniques, in which oxygen is removed via decarbonylation and decarboxylation reactions, are more promising in this respect. ${ }^{7}$ However, mechanistic insights in the catalytic fast pyrolysis of lignin model compounds could only be obtained recently. ${ }^{8}$ To complement and guide cook-and-look approaches, the bottom-up approach suggests that we look at the monomeric species produced upon thermolytic depolymerization with great detail. ${ }^{9}$ Revealing unimolecular decomposition is a fundamental step in addressing the reaction mechanism. This can be achieved by pyrolysis reactors coupled with molecular beam sampling, in order to preserve reactive intermediates and thus allow for mechanistic

\footnotetext{
a. Laboratory for Synchrotron Radiation and Femtochemistry, Paul Scherrer Institute, CH-5234 Villigen PSI, Switzerland; e-mail: patrick.hemberger@psi.ch. ‡present address: Institute of Physical and Theoretical Chemistry, University of Würzburg, Am Hubland, D-97074, Germany

Electronic Supplementary Information (ESI) available: Further time-of-flight mass spectra, ms-TPES for species assignment, computed reaction path and ionization energies. See DOI: 10.1039/x0xx00000x
}

This document is the accepted manuscript version of the following article:

Gerlach, M., Bodi, A., \& Hemberger, P. (2019). Metamorphic meta isomer: carbon dioxide and ketenes are formed via retro-Diels-Alder reactions in the decomposition of metabenzenediol. Physical Chemistry Chemical Physics, 21(35), 19480-19487.

https://doi.org/10.1039/c9cP03519B insights at the molecular level. Advanced methods, such as matrix-IR spectroscopy, ${ }^{10}$ photoionization mass spectrometry (PIMS) ${ }^{11}$ and photoelectron photoion coincidence (PEPICO) ${ }^{12}, 13$ spectroscopy enable isomer-selective detection of reactive intermediates. As far as lignin constituents are concerned, the unimolecular decomposition mechanism has so far been established for benzaldehyde, ${ }^{14}$ phenol, $^{15}$ guaiacol, ${ }^{9}, 16$ dimethoxy benzenes ${ }^{17}$ and catechol ${ }^{18}$ using microreactors.

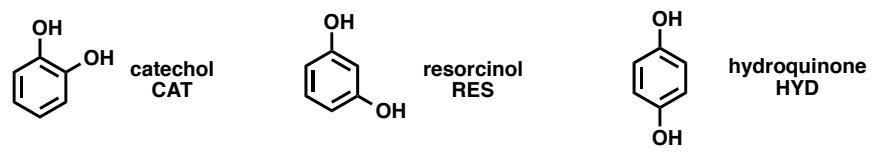

Yang et al. employed a two-stage tubular reactor coupled with GC/MS detection to study the decomposition of benzenediols, and observed a 15-fold increase in $\mathrm{CO}_{2}$ production for resorcinol (RES) compared to the other two isomers. ${ }^{19}$ They also reported a computed biradical driven reaction mechanism for the formation of $\mathrm{CO}_{2}$. However, their kinetics calculations suggested that decarboxylation is not feasible, at odds with their experimental data. ${ }^{20}$ Among the three benzenediols, Ormond et al. found that only the meta isomer resorcinol yields $\mathrm{C}_{5} \mathrm{H}_{6}$ species and $\mathrm{CO}_{2}$, and decarboxylation is completely absent for catechol (CAT) and hydroquinone (HYD). ${ }^{18}$ Similar isomer-selective reactivity was also observed for xylyl radicals. ${ }^{21-23}$ While both ortho- and para-xylyl can easily lose hydrogen to produce the respective xylylenes, this reaction channel is missing in the meta radical, which could only form a high-energy biradical species. ${ }^{24}$ Thus, the 1,3-isomer rearranges first to the 1,2- or 1,4-form before hydrogen is cleaved off. As shown in femtosecond pump-probe experiments, the meta-xylyl also 
follows different excited state dynamics and decays twice as fast from the $D_{3}$ to the ground $D_{1}$ state as the other isomers. ${ }^{25}$

Ormond et al. also observed the ethenone, an elusive ketene $(\mathrm{m} / \mathrm{z}$ 42 ), in the photoionization mass spectra of resorcinol. ${ }^{18}$ Ketenes have recently been in the limelight as important intermediates in zeolite catalysis, as well. ${ }^{26}$ Chowdhury and Gascon raised the question whether they play an important role only as precursors for acetate species on the catalyst surface or if they are actively involved in the catalytic cycle. This motivated us to investigate the decomposition of resorcinol to elucidate the reaction mechanism including ketene formation and decarboxylation.

We have used molecular beam sampling of an in-vacuum flash pyrolysis microreactor coupled to photoelectron photoion coincidence (PEPICO) detection. This technique has been proven to be a sensitive and multiplexed tool to study chemical reactions and detect elusive species in the gas phase ${ }^{13}$ upon photolysis, 27,28 fluorine abstraction, ${ }^{29,} 30$ as well as in combustion, ${ }^{31-33}$ catalysis $^{8,34-36}$ and pyrolysis processes. ${ }^{24,37,38}$

\section{Experimental \& Calculations}

The experiments were carried out at the vacuum ultraviolet beamline of the Swiss Light Source (SLS) at Paul Scherrer Institute (PSI). The setup consists of a pyrolysis reactor combined with the CRF-PEPICO double imaging photoelectron photoion coincidence (i2PEPICO) spectrometer. The beamline and the PEPICO endstation were described previously $\mathrm{y}^{39,40}$ and only a brief summary is presented here.

Resorcinol (Sigma-Aldrich, $>99 \%$ ) was loaded into a heatable container with a $100 \mu \mathrm{m}$ pinhole and was held at $85^{\circ} \mathrm{C}$ providing a vapor pressure of 0.14 mbar, which, at a backing pressure of 320 mbar of $\mathrm{Ar}$, results in a dilution of $0.04 \% .^{41}$ The gas mixture was expanded through the pinhole at a flow rate of $50 \mathrm{sccm}$ Ar into a $3 \mathrm{~cm}$ long resistively heated $\mathrm{SiC}$ tube with an internal diameter of $1 \mathrm{~mm}$. The surface temperature of the reactor was varied between room temperature and $1500{ }^{\circ} \mathrm{C}$. Based on the study by Guan et al., we estimate the pressure in the reactor to be on the order of $10 \mathrm{mbar}$ in the reaction zone. ${ }^{42}$ The gas temperature in the reactor may be up to $300 \mathrm{~K}$ lower compared to the surface temperature as measured by a type $\mathrm{C}$ thermocouple. Kinetic analysis would require accurate ionization cross sections as well as flows and conditions (temperatures, pressures) in the microreactor, allowing for the full modelling of the reactions, ${ }^{42-45}$ which is outside the scope of the current study.

VUV synchrotron radiation was generated by a bending magnet, dispersed on a 150 grooves per $\mathrm{mm}$ grating and focused on the exit slit. The light passed through a $\mathrm{MgF}_{2}$ window or a gas filter ( $\mathrm{Ne} / \mathrm{Ar}$ ) to absorb higher order radiation, then it crossed the molecular beam. The resulting photoelectrons and -ions were extracted in opposite direction by a constant $220 \mathrm{~V} \mathrm{~cm}^{-1}$ field. The electrons were velocity map imaged on a RoentDek (DLD40) delay line anode detector. The position of the electron on the detector gives insight into its kinetic energy, with threshold electrons detected at the centre of the detector. Electrons also served as start signal for the time-of-flight measurement of the coincident ion. The ions were detected in space focussing conditions using a second RoentDek delay line anode detector. The photon energy was scanned from 8 to $11 \mathrm{eV}$ in steps of $0.02 \mathrm{eV}$. Electrons with non-zero kinetic energy may also hit the detector centre if their original momentum vector is parallel to the extraction axis. To eliminate the contribution of these energetic electrons the hot electron signal was subtracted as described in the literature. ${ }^{46}$ The photoion mass-selected threshold photoelectron spectrum (ms-TPES) is obtained by plotting the threshold ionization cation signal in an $\mathrm{m} / \mathrm{z}$ channel as a function of the photon energy. ${ }^{39}$

Franck-Condon simulations of the ms-TPES were performed in the double harmonic approximation by (time-dependent) density functional theory, (TD-)DFT, methods at B3LYP/6-311++G(2d,p) level of theory as implemented in the Gaussian suite of programs (16 rev A.03). ${ }^{47}$ The geometry of the neutral and ion were optimized and the force constant matrix was used to calculate the FC spectrum at a temperature of $500 \mathrm{~K}$. lonization energies of reactants, products, and intermediates were calculated with the G4 composite method. ${ }^{48}$ Transition state structures were also calculated along the reaction paths via a Berny search or using synchronous transit-guided quasiNewton (STQN) methods. ${ }^{49}$ Stationary points were confirmed to be minima or transition states by vibrational analysis. The normal mode with the imaginary frequency was confirmed to correspond to the reaction coordinate in transition states.

\section{Results \& Discussion}

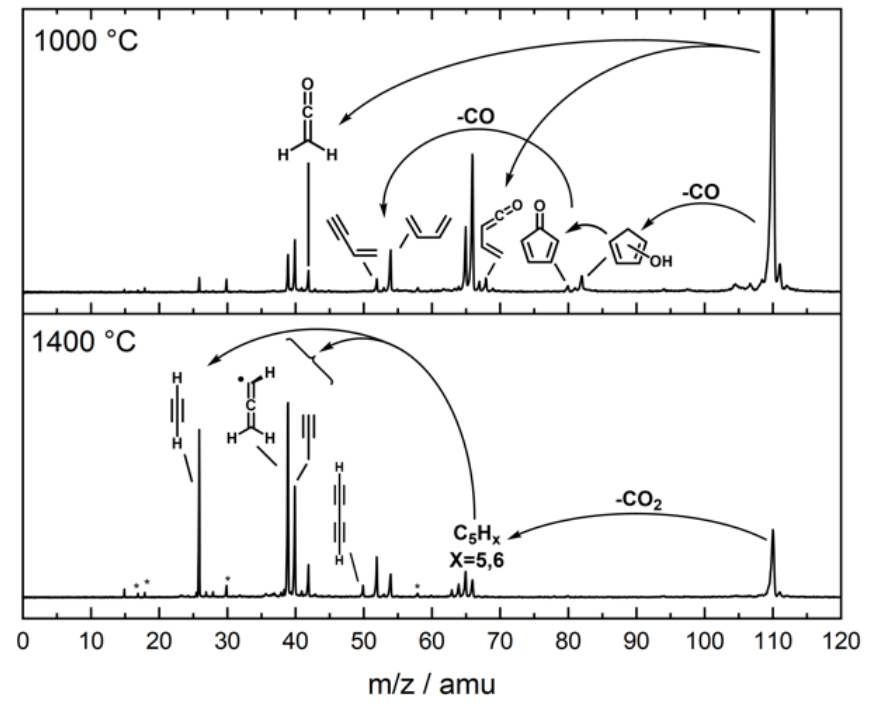

Figure 1. PIMS of $0.04 \%$ resorcinol in argon at different reactor temperatures and 11.5 $\mathrm{eV}$ photon energy. As indicated by the proposed reaction channels, thermal decomposition is driven by ketene, $\mathrm{CO}$, and $\mathrm{CO}_{2}$ losses.

Dissociative photoionization is suppressed by the low photon energy used in the photoionization mass spectra (PIMS) shown in Figure 1 and the numerous peaks predominantly correspond to intact neutral molecules leaving the reactor and evidence rich unimolecular 
chemistry. Further PIMS at different thermal conditions and photon energies can be found in Figure S1 (ESI). The assigned molecules, unless specified otherwise, were isomer-selectively identified by their ms-TPES, as compared to literatur ${ }^{31,50-55}$ data or FC simulations (see ESI).

First, akin to ortho- and para-dihydroxybenzene, resorcinol may undergo $\mathrm{CO}$ loss to form hydroxycyclopentadiene $\left(\mathrm{C}_{5} \mathrm{H}_{5} \mathrm{OH}, \mathrm{m} / \mathrm{z} 82\right)$, which can decompose to cyclopentadienone $(\mathrm{m} / \mathrm{z} 80)$, after two consecutive hydrogen atom loss reactions (see R1): $: 16$

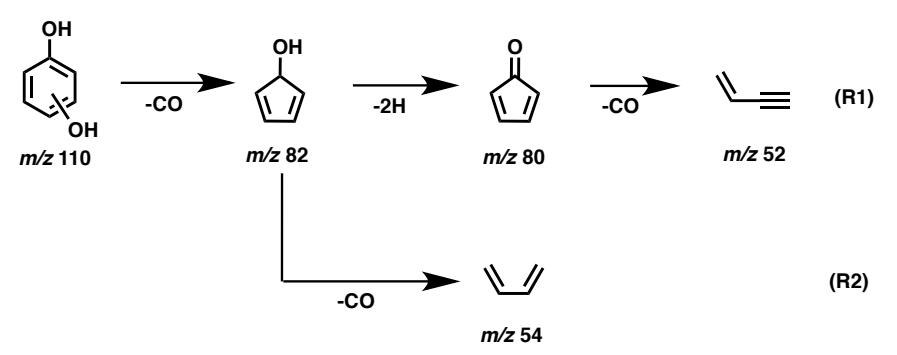

Hydroxycyclopentadiene $(\mathrm{m} / \mathrm{z}$ 82) undergoes large geometry change upon ionization, which results in a broad and featureless ms-TPES (see ESI). Therefore, the $\mathrm{m} / \mathrm{z} 82$ peak is one of the few that we cannot unambiguously assign isomer specifically. Hydroxycyclopentadiene $(\mathrm{m} / \mathrm{z} 82)$ and cyclopentadienone $(\mathrm{m} / \mathrm{z} 80)$ may also undergo CO loss to form butadiene $(\mathrm{m} / \mathrm{z} 54, \mathbf{R 2})$ and vinylacetylene ( $m / z 52, \mathbf{R} 1)$, respectively. ${ }^{56}$ Additionally, diacetylene $(\mathrm{m} / \mathrm{z} 50)$ may be generated by hydrogen loss of vinylacetylene. At higher temperatures, these species likely undergo further fragmentation to yield acetylene $(m / z 26)$ as observed in the photoionization mass spectrum in Figure 1 and described in R3:

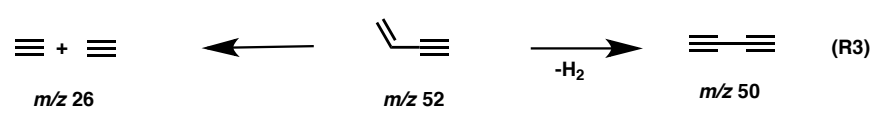

Second, we observe $m / z 66\left(\mathrm{C}_{5} \mathrm{H}_{6}\right)$ which is the direct decarboxylation $\left(\mathrm{CO}_{2}\right.$-loss) product of resorcinol. Judging by its intensity, this is the kinetically favoured reaction channel at temperatures as high as $1000{ }^{\circ} \mathrm{C}$. In contrast, decarboxylation was not present for catechol and only very slightly for hydroquinone. ${ }^{57}$ This is in accordance with the mentioned experimental study using GC/MS detection, which compared the three benzenediols. Here resorcinol showed a 15 -fold increase in decarboxylation compared to the other two isomers. ${ }^{19}$

$\mathrm{C}_{5} \mathrm{H}_{6}$ can further decompose to yield either $\mathrm{C}_{5} \mathrm{H}_{5}$ radicals and hydrogen or to acetylene $(\mathrm{m} / \mathrm{z} 26)$ and propyne/allene $(\mathrm{m} / \mathrm{z} 40)$. Cyclopentadienyl $\left(\mathrm{C}_{5} \mathrm{H}_{5}\right)$ dissociates to propargyl $\left(\mathrm{C}_{3} \mathrm{H}_{3}, \mathrm{~m} / z\right.$ 39) and acetylene, as summarized in $\mathbf{R} \mathbf{4}: 37,57$

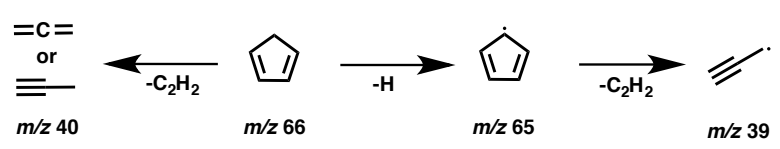

The $\mathrm{C}_{5} \mathrm{H}_{6}$ ms-TPES changes significantly with pyrolysis temperature and is analysed in detail below. $\mathrm{C}_{5} \mathrm{H}_{5}$ was assigned to the cyclopentadienyl radical (see ESI).
Third, a channel is observed to yield ketene $(\mathrm{m} / \mathrm{z} 42)$, as confirmed by its ms-TPES and the reference spectrum by Felsmann et al. in Figure 2. ${ }^{31}$ Ketene was absent for both hydroquinone and catechol and thus marks an exclusive channel for the meta isomer resorcinol. We also found the $\mathrm{m} / \mathrm{z} 68$ counter fragment at lower reactor temperatures, which was identified as buta-1,3-dienal on the basis of a Franck-Condon simulation. This reaction channel is not accessible in the ortho and para isomer and is summarized as follows:

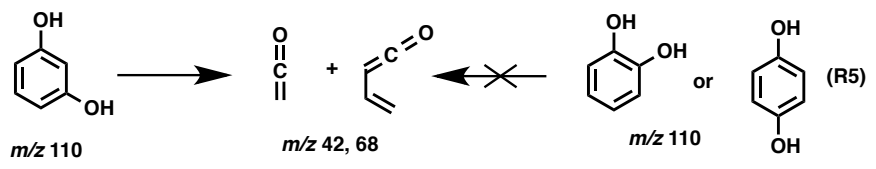

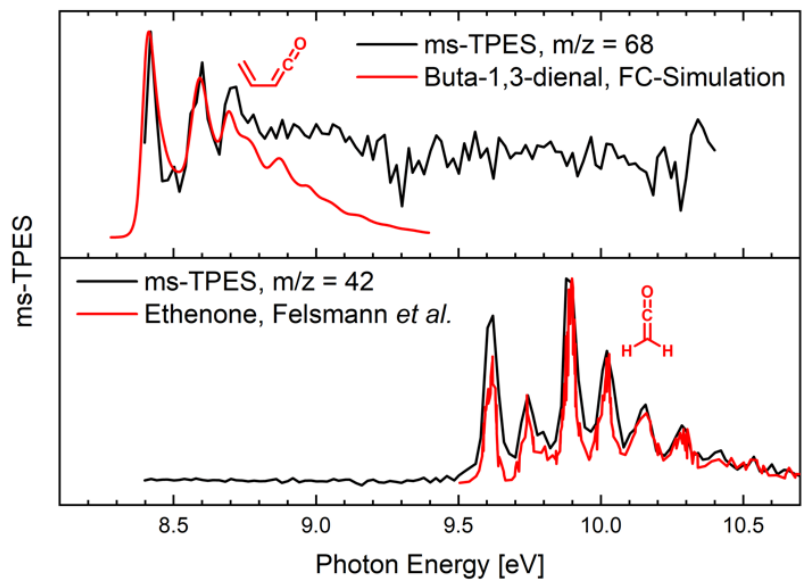

Figure 2. ms-TPE spectra of $m / z 42$ and 68 . Thanks to the reference spectrum and the FC simulation, these intermediates can be assigned to the ketenes ethenone and buta1,3-dienal.

The direct water loss to yield fulvenone $\left(c-\mathrm{C}_{5} \mathrm{H}_{4}=\mathrm{C}=\mathrm{O}, \mathrm{m} / \mathrm{z}\right.$ 92) was not observed upon decomposition of resorcinol and appears exclusively in case of catechol, owing to the close proximity of the

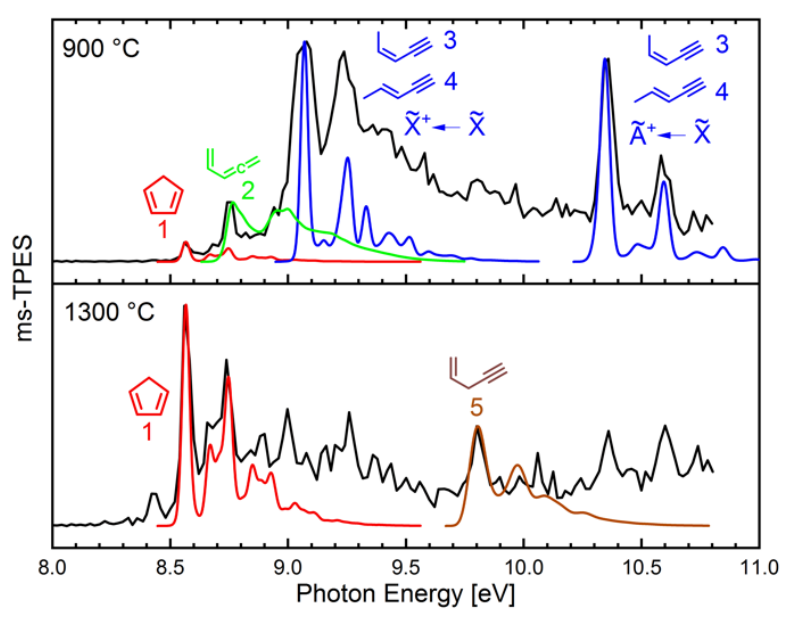

Figure 3. ms-TPE spectrum of $m / z 66$ as a function of reactor temperature. Thanks to FC simulations all the features can be explained in the spectrum. The acyclic isomers penta-1,2,4-triene (2), and Z- and E-1-pentyne-3-ene $(\mathbf{3}, \mathbf{4})$ dominate the spectrum at $900{ }^{\circ} \mathrm{C}$ reactor temperature. Above $1300{ }^{\circ} \mathrm{C}$, cyclopentadiene $(\mathbf{1})$ and traces of 1 pentyne-4-ene (5) are the spectral carriers. 


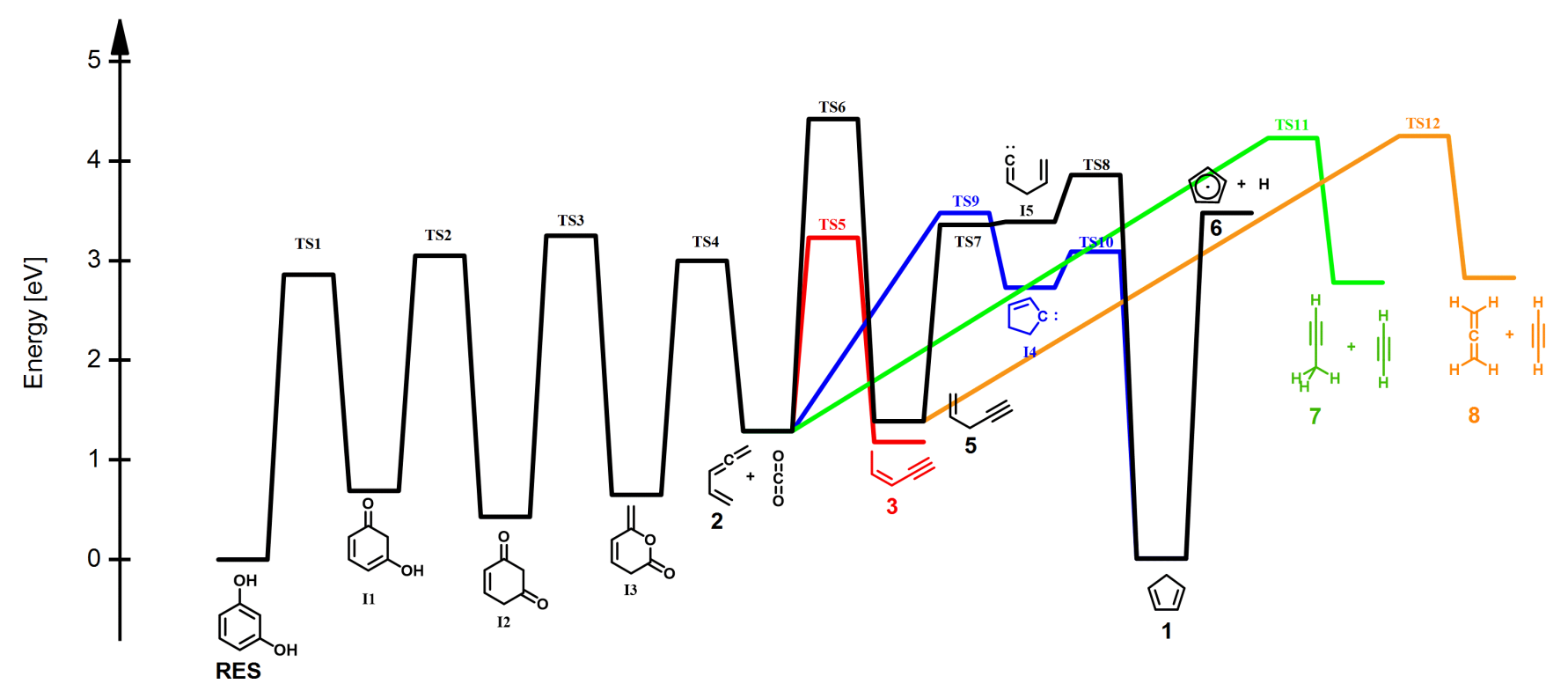

Figure 4. Potential energy surface of the unimolecular decomposition of resorcinol (RES). After two keto-enol tautomerization steps (RES $\rightarrow$ TS1 $\rightarrow$ I $\rightarrow$ TS2 $\rightarrow$ I2) a retro-DielsAlder reaction yields penta-1,2,4-triene $\mathbf{2}$ and $\mathrm{CO}_{2} . \mathbf{2}$ can rearrange to yield $\mathbf{3}$ (TS5) or cyclopentadiene $\mathbf{1}$ (TS9, TS 10). 1 can further decompose to produce cyclopentadienyl radicals or allene $\mathbf{6}$ and propyne $\mathbf{7}$ together with acetylene.

two hydroxyl groups. At $14.1 \mathrm{eV}$, we observe both $\mathrm{m} / \mathrm{z} 28$ and 44 (CO and $\mathrm{CO}_{2}$ ), which also show temperature dependence (see Figure S2 in ESI) and are the counter fragments of the hydroxycyclopentadiene and $\mathrm{C}_{5} \mathrm{H}_{6}$ formation.

The $\mathrm{m} / \mathrm{z} 66 \mathrm{~ms}$-TPES at two different reactor temperatures is presented in Figure 3, along with FC simulations. Together with G4 ionization energy calculations several $\mathrm{C}_{5} \mathrm{H}_{6}$ isomers were assigned at the two temperatures. In total, the spectra of 13 different $\mathrm{C}_{5} \mathrm{H}_{6}$ isomers were simulated and the best fits are summarized in Figure 2. At $900^{\circ} \mathrm{C}$, several peaks are present. The most abundant one at 9.08 $\mathrm{eV}$ corresponds to the fundamental transition of pent-3-en-1-yne (3 \& 4, blue simulation) with a calculated adiabatic ionization energy (IE) of $9.07 \mathrm{eV}$ (blue). The bands at 10.35 and $10.58 \mathrm{eV}$ are too high in energy to belong to a transition to the electronic ground state cation of any of the $\mathrm{C}_{5} \mathrm{H}_{6}$ isomers. The TD-DFT calculated IE to the first excited state at $10.36 \mathrm{eV}$ and the FC simulation of the 3-penten1-yne photoelectron spectrum agree very well with the experiment in this energy range. The assignment is further corroborated by the observation that the peaks at $9.08 \mathrm{eV}$ and $10.35 \mathrm{eV}$ show constant relative intensity at different reactor temperatures, hence both peaks originate from the same species. Note that we have calculated the ionization energies and simulated the spectra of both Z- (3) and $\mathrm{E}$ - (4) isomers. They were found to be virtually identical, and only the cis spectrum (3) is depicted in Figure 3. However, it is likely that both species are formed or that their interconversion is fast at the experimental temperature.

The low-energy features starting at $8.56 \mathrm{eV}$ arise from formation of cyclopentadiene $\mathrm{c}_{-} \mathrm{C}_{5} \mathrm{H}_{6} \mathbf{1}$. The IE is in good agreement with the reported AIE of $8.57 \mathrm{eV}$ and the reference spectrum. ${ }^{58} \mathrm{At} 8.75 \mathrm{eV}$, a medium intense transition is observed, which is not reproduced by the reference spectrum of $\mathrm{c}-\mathrm{C}_{5} \mathrm{H}_{6}$, but can be assigned to the $0 \rightarrow 0$ transition of penta-1,2,4-triene 2 , with a calculated IE of $8.70 \mathrm{eV}$.

The ms-TPES at $1300{ }^{\circ} \mathrm{C}$ shows a much simpler picture, where the most prominent species is cyclopentadiene $\mathbf{1}$, with smaller contributions from pent-4-en-1-yne $\mathbf{5}$, which possesses a strong fundamental transition at $9.80 \mathrm{eV}$ (calc. IE $=9.81 \mathrm{eV}$ ). Thus, the msTPE spectrum of $\mathrm{m} / \mathrm{z} 66, \mathrm{C}_{5} \mathrm{H}_{6}$, shows contributions of four constitutional isomers, and is dominated by cyclopentadiene at elevated temperatures. How can resorcinol lose $\mathrm{CO}_{2}$ to yield $\mathrm{C}_{5} \mathrm{H}_{6}$ species? Why does cyclopentadiene, the most stable isomer, only appear at high temperatures? Why is $\mathrm{CO}_{2}$ loss and ketene formation absent in the other two benzenediol isomers? To answer these questions, we explored the potential energy surface of resorcinol. Resorcinol has to rearrange in order to have both oxygen atoms on the leaving carbon atom before it can lose $\mathrm{CO}_{2}$. The lowest lying path for this rearrangement is shown in Figure 4. Two consecutive ketoenol-tautomerizations (over TS1 and TS2) lead to the 1,3-diketone I2. By rearrangement over a 4-membered ring transition state (TS3) the lactone 13 is formed. Via a retro-Diels-Alder (TS4) reaction, 13 can then decarboxylate to penta-1,2,4-triene 2, with a rate limitingbarrier at $3.25 \mathrm{eV}$ relative to resorcinol. This reaction channel is around $0.5 \mathrm{eV}$ lower in energy compared to first hydrogen loss channel, which initiates $\mathrm{CO}_{2}$ loss in the biradical driven reaction mechanism found by Furutani et al. and may explain the discrepancy between their experiment and kinetics calculations. ${ }^{20}$

In order to explain the temperature dependent $\mathrm{C}_{5} \mathrm{H}_{6}$ isomeric composition, we also investigated isomerization reactions between the $\mathrm{C}_{5} \mathrm{H}_{6}$ isomers (Figure 4). Penta-1,2,4-triene 2 can isomerize to pent-3-en-1-yne $\mathbf{3}$ via a sigmatropic [1,5] hydrogen-shift (TS5) over a 


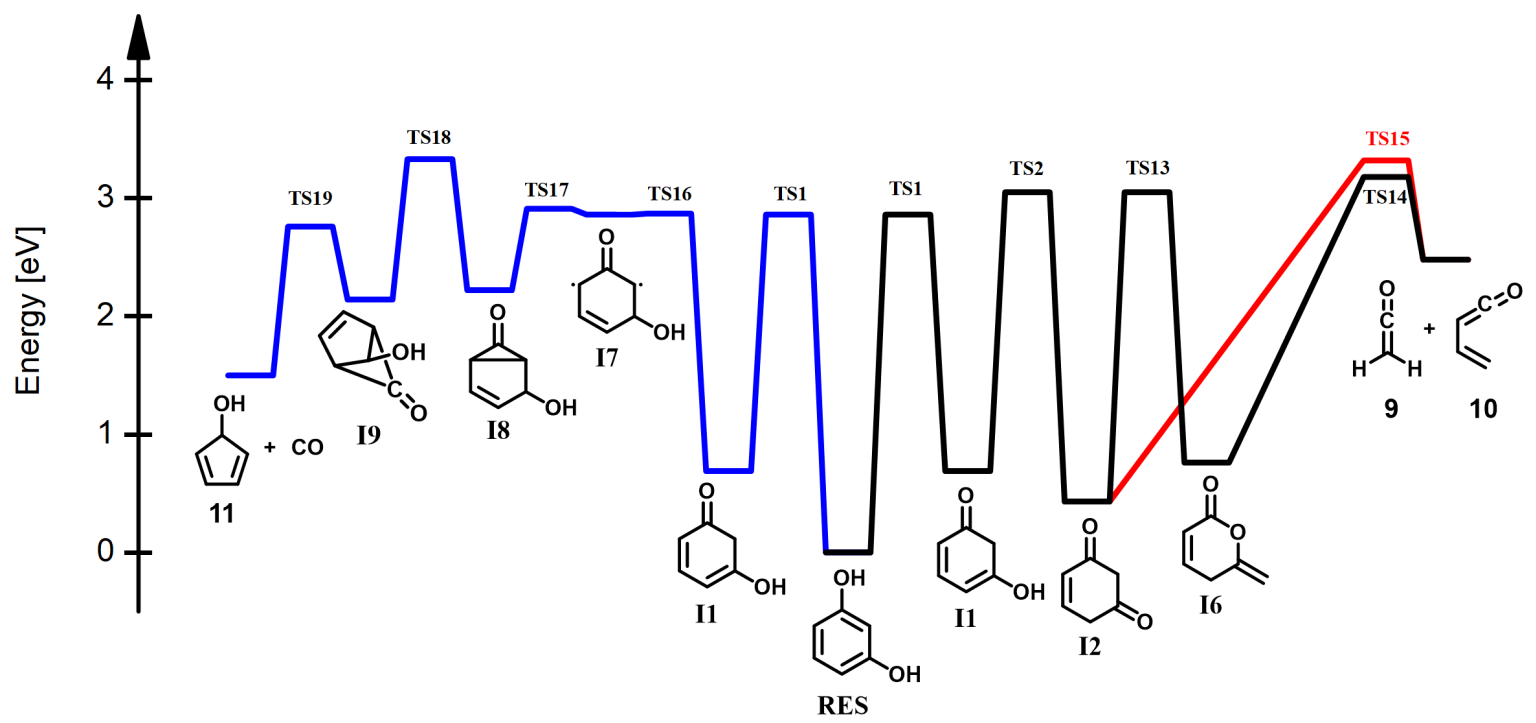

Figure 5: Calculated potential energy surface for the formation of the two ketenes ethenone $\mathbf{9}$ and buta-1,3-dienal $\mathbf{1 0}$ and the hydroxycyclopentadiene $\mathbf{1 1}$. The latter reaction proceeds over a biradical intermediate 17 and two bicyclic species 18 and 19 to afford $\mathrm{CO}$ and hydroxycyclopentadiene. Two reaction pathways for the formation of the two ketenes were found, which open up as high as $3 \mathrm{eV}$ and thus almost isoenergetic to the decarboxylation reaction.

relative barrier of $1.94 \mathrm{eV}$. Assuming comparable ionization cross sections, $\mathbf{3}$ (and $\mathbf{4}$ ) are shown to be most abundant $\mathrm{C}_{5} \mathrm{H}_{6}$ products at $900{ }^{\circ} \mathrm{C}$. Penta-1,2,4-triene 2 may also form pent-4-en-1-yne $\mathbf{5}$ via a sigmatropic [1,3] hydrogen-shift. However, the barrier of $3.13 \mathrm{eV}$ (TS6) is significantly higher than the ring-closing reaction over TS9 $(2.19 \mathrm{eV})$, connecting 2 to cyclopentadiene $\mathbf{1}$. We relied on the previously proposed mechanism computed at the CASPT2/VTZ2P level of theory in exploring this part of the potential energy surface, and recalculated and confirmed the energies at the $\mathrm{G} 4$ level of theory. ${ }^{59}$ Most notably, cyclopentadiene 1 and $\mathrm{CO}_{2}$ are by far the most stable products, only $0.01 \mathrm{eV}$ above resorcinol and about 1.17 $\mathrm{eV}$ below the second most stable $\mathrm{C}_{5} \mathrm{H}_{6}$ isomer, 3 . The transition state energies show that pent-3-en-1-yne $\mathbf{3}$ and, to a smaller extent, cyclopentadiene 1 may be accessible at temperatures required to form penta-1,2,4-triene $\mathbf{2}$ and $\mathrm{CO}_{2}$, as observed by their simultaneous appearance in the ms-TPES. The relatively high barrier from 2 to 5 (TS6) and its low expected abundance when in equilibrium with $\mathbf{1}(\mathbf{1} \leftrightarrow \mathrm{TS} 8 \leftrightarrow \mathbf{5})$ raises doubts whether $\mathbf{5}$ can be formed easily from the other $\mathrm{C}_{5} \mathrm{H}_{6}$ isomers. However, we could neither find a lower lying transition state than TS6 connecting $\mathbf{2}$ and 5 nor could we identify another decarboxylation channel to yield $\mathbf{5}$ from resorcinol. As mentioned above, cyclopentadiene $\mathbf{1}$ is by far the most stable reaction product, and exhibits high barriers to decomposition to yield cyclopentadienyl $\left(\mathrm{c}-\mathrm{C}_{5} \mathrm{H}_{5}\right) \mathbf{6}$ and hydrogen radicals, or propyne $\mathbf{7}$ or allene $\mathbf{8}$ together with acetylene at ratelimiting transition state energies of $3.47 \mathrm{eV}, 4.22 \mathrm{eV}$ (TS11) and 4.24 $\mathrm{eV}$ (TS12), respectively, relative to 1 . Its production is nevertheless inhibited by the relatively high-lying ring-closing transition states. This explains why acyclic isomers are formed at low reactor temperatures, which react further and isomerize to cyclopentadiene or decompose to produce allene/propyne and acetylene at high temperatures. Some cyclopentadiene $\mathrm{c}^{-} \mathrm{C}_{5} \mathrm{H}_{6}$ survives and is always observed. The formation of cyclopentadienyl radicals $\left(c-\mathrm{C}_{5} \mathrm{H}_{5}\right)$ is a source of hydrogen atoms, which can also trigger bimolecular chemistry. Hydrogen atom catalyzed decomposition reactions were discussed in the literature for lignin model compounds and were found to play a role for the formation of benzene and benzyne from benzaldehyde through chain reactions. ${ }^{14}$ In case of resorcinol, we would expect generation of phenol or benzene, ${ }^{17}$ however their appearance was only negligible (see Figure S1) and this reaction pathway only plays a subordinate role:

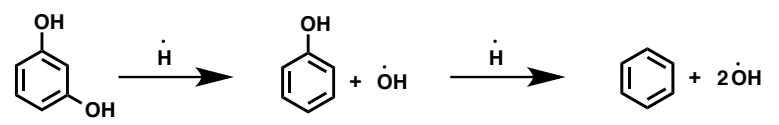

(R6)

In addition to decarboxylation, ketene $\mathbf{9}$ and buta-1,3-dienal $\mathbf{1 0}$ formation (R5) is also exclusively observed in resorcinol and the corresponding potential energy curves are shown in Figure 5 (black and red channels). In fact, ketene and $\mathrm{CO}_{2}$ loss share the same diketone intermediate 12 , unique to the meta substituted resorcinol. Here, we again found that retro-Diels-Alder reactions play an important role: 12 can directly decompose in retro-[4+2] fashion or it rearranges first to 16 (TS13), which follows the same ring-opening reaction (TS14), with a slightly lower-lying transition state compared to TS15, and both channels may open up at about the same temperature.

The CO formation mechanism to afford cyclopenta-1,4-dien-1-ol 11, as the third branch of the decomposition of resorcinol (blue channel Figure 5), is an adapted form of the decarboxylation (CO loss) of phenol, which has been published by Scheer et al. ${ }^{57}$ The mechanism with an additional $\mathrm{OH}$ group proceeds similarly, except for the formation of an additional intermediate 19, which was not identified in the decomposition of phenol. A very similar mechanism is also possible where in the first keto enol tautomerization a hydrogen in 
the 4-position is shifted. This mechanism is energetically similar and leads to cyclopenta-1,4-dien-1-ol and can be found in the SI.

As mentioned above, both the decarboxylation and the ketene channels are absent in hydroquinone and catechol and are unique to the meta-substituted resorcinol isomer. Although keto-enol tautomerization can in principle occur in HYD and CAT, ketene cannot leave in a retro-Diels-Alder fashion (see $\mathbf{R 7}$ and $\mathbf{R 8}$ ):

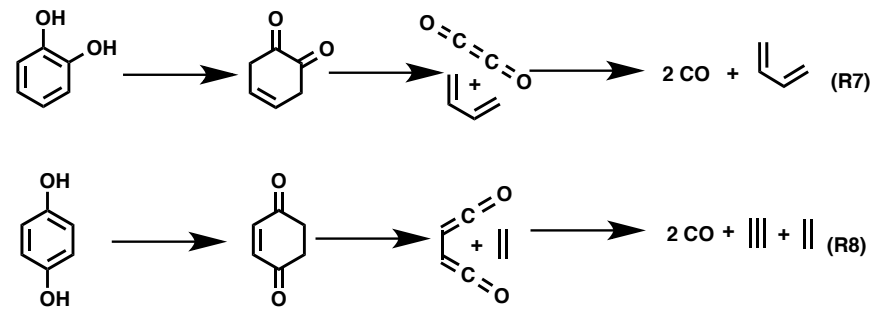

Similar consideration also applies for the $\mathrm{CO}_{2}$ loss, where the relevant isomerization to generate intermediate $\mathrm{I} 3$ cannot proceed in CAT or in HYD as easily as in RES. In fact, seven or five-membered carbene and biradical ring intermediates must be formed prior to decarboxylation. These intermediates do not allow for low-energy retro-cyclisation reactions to occur, rendering these pathways inaccessible.

\section{Summary \& Conclusions}

We have investigated the unimolecular decomposition of resorcinol in the gas phase applying PEPICO as an isomer-selective detection tool for elusive molecules. Three reaction channels were identified for resorcinol and are summarized in R9, R10 and R11:

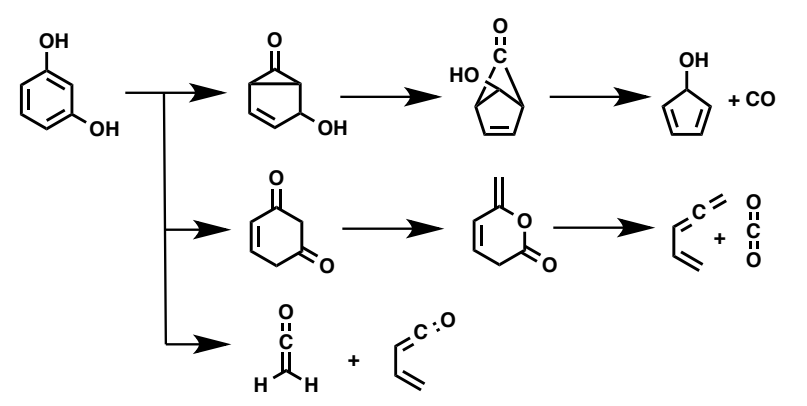

Decarbonylation (CO loss) of resorcinol yields hydroxycyclopentadiene (R9), which is the common reaction pathway for all three benzenediols. Two reaction channels are exclusively observed for meta-benzenediol (RES), emphasizing its isomer-specific reactivity. Ethenone and 1,3-butadienal, two elusive ketene species, are formed in retro-Diels-Alder (R11) reactions and share a common intermediate with $\mathrm{CO}_{2}$ loss. A second rearrangement occurs prior to decarboxylation, where a terminal $\mathrm{CH}_{2}$ group is intermediately generated, which also undergoes retro-[4+2] cycloaddition to yield penta-1,2,4-triene (R10). This then isomerizes to acyclic $\mathrm{C}_{5} \mathrm{H}_{6}$ species as a function of reactor temperature, which may decompose at high temperatures or form the most stable isomer, cyclopentadiene. We have compiled a potential energy surface for the resorcinol decomposition, which explains our experimental findings as well as the literature data. ${ }^{19}$ Furthermore, we have identified a novel, energetically efficient pathway for the decarboxylation, which can rationalize the literature observation that $\mathrm{CO}_{2}$ loss is a dominating channel upon resorcinol decomposition. ${ }^{20}$ Cyclopentadiene $\left(\mathrm{c}-\mathrm{C}_{5} \mathrm{H}_{6}\right)$ yields allene/propyne or cyclopentadienyl radicals, which form propargyl and acetylene at very high reactor temperatures. Cyclopentadienyl, as a resonantly stabilized radical, is known to participate in the formation of polycyclic aromatic hydrocarbons (PAH), as represented by its simplest reaction, the dimerization to form naphthalene: 60
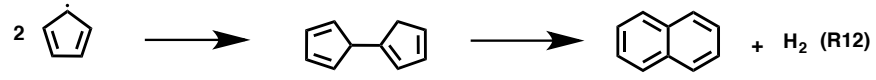

Thus the appearance of cyclopentadienyl radicals, unique to the decomposition of the meta isomer resorcinol, may be a potential source of coke in lignin catalytic fast pyrolysis. A second source of coke is attributed to the formation of the ketene species ethenone upon decomposition of resorcinol. Ethenone was found to be responsible for the production of $\mathrm{C}-\mathrm{C}$ bonds in methanol-to-olefin (MTO) and other, carbonylation reactions. We speculate that the appearance of ethenone in zeolite-catalyzed fast pyrolysis of lignin may open up additional pathways to produce $\mathrm{C}-\mathrm{C}$ bonds. Thus, this carbon growth may also be a reason for the formation of coke-prone aromatic species, responsible for pore-blocking and the deactivation of the catalyst. ${ }^{26}$ Hence, the role of ketenes in zeolite catalysis should be further addressed to improve the understanding of these processes. Furthermore, understanding the gas phase chemistry of the lignin decomposition is an important step towards elucidating the underlying reaction mechanism of catalytic lignin pyrolysis, as it is probably the result of an interplay of gas-phase and surfaceconfined steps, ${ }^{8}$ as was shown most recently for oxyhalogenation reactions. ${ }^{34,35}$

\section{Conflicts of interest}

There are no conflicts to declare.

\section{Acknowledgements}

The measurements were carried out at the VUV beamline of the Swiss Light Source at Paul Scherrer Institute in Villigen, Switzerland. A.B and P.H gratefully acknowledge funding by the Swiss Federal Office of Energy (SFOE SI/501269-01) and the Swiss National Science Foundation (SNF 200021_178952). We thank Patrick Ascher for technical assistance.

\section{References}


1. W. Mu, H. Ben, A. Ragauskas and Y. Deng, Bioenergy Res., 2013, 6 , $1183-1204$

2. P. Azadi, O. R. Inderwildi, R. Farnood and D. A. King, Renew. Sust. Energ. Rev., 2013, 21, 506-523.

3. J. Zakzeski, P. C. A. Bruijnincx, A. L. Jongerius and B. M. Weckhuysen, Chem. Rev., 2010, 110, 3552-3599.

4. R. Rinaldi, R. Jastrzebski, M. T. Clough, J. Ralph, M. Kennema, P. C. A. Bruijnincx and B. M. Weckhuysen, Angew. Chem. Int. Ed., 2016, 55, 8164-8215.

5. L. Chen, J. Xin, L. Ni, H. Dong, D. Yan, X. Lu and S. Zhang, Green Chem., 2016, 18, 2341-2352.

6. H. Lee, H. Kim, M. J. Yu, C. H. Ko, J.-K. Jeon, J. Jae, S. H. Park, S.-C. Jung and Y.-K. Park, Sci. Rep., 2016, 6, 28765.

7. T. Dickerson and J. Soria, Energies, 2013, 6, 514-538.

8. P. Hemberger, V. B. F. Custodis, A. Bodi, T. Gerber and J. A. van Bokhoven, Nat. Commun., 2017, 8, 15946.

9. V. B. F. Custodis, P. Hemberger, Z. Ma and J. A. van Bokhoven, J. Phys. Chem. B, 2014, 118, 8524-8531.

10. R. A. Moss, M. S. Platz and J. Maitland Jones, Reactive Intermediate Chemistry, Wiley Interscience, New York, 2003.

11. O. Kostko, B. Bandyopadhyay and M. Ahmed, Annu. Rev. Phys. Chem., 2016, 67, 19-40.

12. T. Baer and R. P. Tuckett, Phys. Chem. Chem. Phys., 2017, 19, 9698-9723.

13. P. Hemberger and A. Bodi, Chimia, 2018, 72, 227-232.

14. A. K. Vasiliou, J. H. Kim, T. K. Ormond, K. M. Piech, K. N. Urness, A. M. Scheer, D. J. Robichaud, C. Mukarakate, M. R. Nimlos, J. W. Daily, Q. Guan, H.-H. Carstensen and G. B. Ellison, J. Chem. Phys., 2013, 139, 104310.

15. A. M. Scheer, C. Mukarakate, D. J. Robichaud, M. R. Nimlos, H.-H. Carstensen and G. B. Ellison, J. Chem. Phys., 2012, 136, 044309.

16. A. M. Scheer, C. Mukarakate, D. J. Robichaud, M. R. Nimlos and G. B. Ellison, J. Phys. Chem. A, 2011, 115, 13381-13389.

17. D. J. Robichaud, A. M. Scheer, C. Mukarakate, T. K. Ormond, G. T. Buckingham, G. B. Ellison and M. R. Nimlos, J. Chem. Phys., 2014, 140, 234302.

18. T. K. Ormond, J. H. Baraban, J. P. Porterfield, A. M. Scheer, P. Hemberger, T. P. Troy, M. Ahmed, M. R. Nimlos, D. J. Robichaud, J. W. Daily and G. B. Ellison, J. Phys. Chem. A, 2018, 122, 5911-5924.

19. H. Yang, Y. Furutani, S. Kudo, J.-i. Hayashi and K. Norinaga, J. Anal. Appl. Pyrolysis, 2016, 120, 321-329.

20. Y. Furutani, S. Kudo, J.-i. Hayashi and K. Norinaga, J. Phys. Chem. A, 2017, 121, 631-637.

21. P. Hemberger, A. J. Trevitt, T. Gerber, E. Ross and G. da Silva, J. Phys. Chem. A, 2014, 118, 3593-3604.

22. P. Hemberger, A. J. Trevitt, E. Ross and G. da Silva, J. Phys. Chem. Lett., 2013, 4, 2546-2550.

23. T. Bierkandt, P. Hemberger, P. Oßwald, M. Köhler and T. Kasper, Proc. Combust. Inst., 2017, 36, 1223-1232.

24. M. Steglich, V. B. F. Custodis, A. J. Trevitt, G. daSilva, A. Bodi and P. Hemberger, J. Am. Chem. Soc., 2017, 139, 14348-14351.

25. M. Steglich, G. Knopp and P. Hemberger, Phys. Chem. Chem. Phys., 2019, 21, 581-588.

26. A. D. Chowdhury and J. Gascon, Angew. Chem. Int. Ed., 2018, 57, 14982-14985.

27. D. Schleier, P. Constantinidis, N. Faßheber, I. Fischer, G. Friedrichs, P. Hemberger, E. Reusch, B. Sztáray and K. Voronova, Phys. Chem. Chem. Phys., 2018, 20, 10721 10731.
28. K. Voronova, K. M. Ervin, K. G. Torma, P. Hemberger, A. Bodi, T. Gerber, D. L. Osborn and B. Sztáray, J. Phys. Chem. Lett., 2018, 9, 534-539.

29. D. Schleier, A. Humeniuk, E. Reusch, F. Holzmeier, D. NunezReyes, C. Alcaraz, G. A. Garcia, J.-C. Loison, I. Fischer and R. Mitric, J. Phys. Chem. Lett., 2018, 9, 5921-5925.

30. G. A. Garcia, B. Gans, J. Krüger, F. Holzmeier, A. Röder, A. Lopes, C. Fittschen, C. Alcaraz and J.-C. Loison, Phys. Chem. Chem. Phys., 2018, 20, 8707-8718.

31. D. Felsmann, K. Moshammer, J. Krüger, A. Lackner, A. Brockhinke, T. Kasper, T. Bierkandt, E. Akyildiz, N. Hansen, A. Lucassen, P. Oßwald, M. Köhler, G. A. Garcia, L. Nahon, P. Hemberger, A. Bodi, T. Gerber and K. Kohse-Höinghaus, Proc. Combust. Inst., 2015, 35, 779-786.

32. J. Krüger, G. A. Garcia, D. Felsmann, K. Moshammer, A. Lackner, A. Brockhinke, L. Nahon and K. Kohse-Höinghaus, Phys. Chem. Chem. Phys., 2014, 16, 22791-22804.

33. P. Oßwald, H. Güldenberg, K. Kohse-Höinghaus, B. Yang, T. Yuan and F. Qi, Combust. Flame, 2011, 158, 2-15.

34. V. Paunović, P. Hemberger, A. Bodi, N. López and J. PérezRamírez, Nat. Cat., 2018, 1, 363-370.

35. G. Zichittella, M. Scharfe, B. Puertolas, V. Paunovic, P. Hemberger, A. Bodi, L. Szentmiklosi, N. Lopez and J. PerezRamirez, Angew. Chem. Int. Ed. Engl., 2019, 58, 5877-5881.

36. V. Paunović, G. Zichittella, P. Hemberger, A. Bodi and J. PérezRamírez, ACS Catalysis, 2019, 9, 1710-1725.

37. P. Hemberger, G. da Silva, A. J. Trevitt, T. Gerber and A. Bodi, Phys. Chem. Chem. Phys., 2015, 17, 30076-30083.

38. H. Dossmann, G. A. Garcia, L. Nahon, B. K. C. d. Miranda and C. Alcaraz, J. Chem. Phys., 2012, 136, 204304.

39. B. Sztáray, K. Voronova, K. G. Torma, K. J. Covert, A. Bodi, P. Hemberger, T. Gerber and D. L. Osborn, J. Chem. Phys., 2017, 147, 013944.

40. M. Johnson, A. Bodi, L. Schulz and T. Gerber, Nucl. Inst. Meth. A., 2009, 610, 597-603.

41. S. P. Verevkin and S. A. Kozlova, Thermochim. Acta, 2008, 471, 33-42.

42. Q. Guan, K. N. Urness, T. K. Ormond, D. E. David, G. Barney Ellison and J. W. Daily, Int. Rev. Phys. Chem., 2014, 33, 447-487.

43. M. V. Zagidullin, R. I. Kaiser, D. P. Porfiriev, I. P. Zavershinskiy, M. Ahmed, V. N. Azyazov and A. M. Mebel, J. Phys. Chem. A, 2018, 122, 8819-8827.

44. P. J. Weddle, C. Karakaya, H. Y. Zhu, R. Sivaramakrishnan, K. Prozument and R. J. Kee, Int. J. Chem. Kinet., 2018, 50, 473480.

45. R. S. Tranter, A. L. Kastengren, J. P. Porterfield, J. B. Randazzo, J. P. A. Lockhart, J. H. Baraban and G. B. Ellison, Proc. Combust. Inst., 2017, 36, 4603-4610.

46. B. Sztáray and T. Baer, Rev. Sci. Instrum., 2003, 74, 3763-3768.

47. M. J. Frisch, G. W. Trucks, H. B. Schlegel, G. E. Scuseria, M. A. Robb, J. R. Cheeseman, G. Scalmani, V. Barone, B. Mennucci, G. A. Petersson, H. Nakatsuji, M. Caricato, X. Li, H. P. Hratchian, A. F. Izmaylov, J. Bloino, G. Zheng, J. L. Sonnenberg, M. Hada, M. Ehara, K. Toyota, R. Fukuda, J. Hasegawa, M. Ishida, T. Nakajima, Y. Honda, O. Kitao, H. Nakai, T. Vreven, J. A. Montgomery, J. E. Peralta, F. Ogliaro, M. Bearpark, J. J. Heyd, E. Brothers, K. N. Kudin, V. N. Staroverov, R. Kobayashi, J. Normand, K. Raghavachari, A. Rendell, J. C. Burant, S. S. Iyengar, J. Tomasi, M. Cossi, N. Rega, J. M. Millam, M. Klene, J. E. Knox, J. B. Cross, V. Bakken, C. Adamo, J. Jaramillo, R. Gomperts, R. E. Stratmann, O. Yazyev, A. J. Austin, R. Cammi, C. Pomelli, J. 
W. Ochterski, R. L. Martin, K. Morokuma, V. G. Zakrzewski, G. A. Voth, P. Salvador, J. J. Dannenberg, S. Dapprich, A. D. Daniels, Farkas, J. B. Foresman, J. V. Ortiz, J. Cioslowski and D. J. Fox, Wallingford CT, 2016, DOI: citeulike-articleid:9096580, .

48. L. A. Curtiss, P. C. Redfern and K. Raghavachari, J. Chem. Phys., 2007, 126, 084108.

49. C. Peng and H. Bernhard Schlegel, Isr. J. Chem., 1993, 33, 449454.

50. A. Bodi, P. Hemberger, D. L. Osborn and B. Sztaray, J Phys Chem Lett, 2013, 4, 2948-2952.

51. F. Brogli, E. Heilbronner, V. Hornung and E. Kloster-Jensen, Helv. Chim. Acta, 1973, 56, 2171-2178.

52. F. Brogli, E. Heilbronner, J. Wirz, E. Kloster-Jensen, R. G. Bergman, K. P. C. Vollhardt and A. J. Ashe, Helv. Chim. Acta, 1975, 58, 2620-2645.

53. B. K. Cunha de Miranda, C. Alcaraz, M. Elhanine, B. Noller, P. Hemberger, I. Fischer, G. A. Garcia, H. Soldi-Lose, B. Gans, L. A. Mendes, S. Boye-Peronne, S. Douin, J. Zabka and P. Botschwina, J. Phys. Chem. A, 2010, 114, 4818-4830.

54. P. Forster, J. P. Maier and F. Thommen, Chem. Phys., 1981, 59, 85-90.

55. T. K. Ormond, P. Hemberger, T. P. Troy, M. Ahmed, J. F. Stanton and G. B. Ellison, Mol. Phys., 2015, 113, 2350-2358.

56. T. K. Ormond, A. M. Scheer, M. R. Nimlos, D. J. Robichaud, T. P. Troy, M. Ahmed, J. W. Daily, T. L. Nguyen, J. F. Stanton and G. B. Ellison, J. Phys. Chem. A, 2015, 119, 7222-7234.

57. A. M. Scheer, C. Mukarakate, D. J. Robichaud, M. R. Nimlos, H.-H. Carstensen and G. B. Ellison, 2012, 136, 044309.

58. J. L. Holmes and D. McGillivray, Org. Mass Spectrom., 1971, 5, 1349-1362.

59. G. B. Bacskay and J. C. Mackie, Phys. Chem. Chem. Phys., 2001, 3, 2467-2473.

60. C. F. Melius, M. E. Colvin, N. M. Marinov, W. J. Pit and S. M. Senkan, Symposium (International) on Combustion, 1996, 26, 685-692. 